\title{
Risk Factors of Thrombosis of Pancreatic Graft: A Review
}

\author{
Farhan Asghar ${ }^{1}$, Jun Hu${ }^{1}$, Shijie Zhong ${ }^{1}$, Hanlin Yao ${ }^{1}$, Zongze $\mathrm{Qi}^{1}$, Yong Hou ${ }^{1}$, Yunfei Luo ${ }^{1}$ and Hong Zhu ${ }^{2}$ \\ ${ }^{1}$ Department of Hepatobillary and Pancreatic Surgery of Second Affiliated Hospital, Kunming Medical University, China \\ ${ }^{2}$ First Division of Hepatobillary and Pancreatic Surgery of Second Affiliated Hospital, Kunming Medical University, China
}

*Corresponding author: Hong Zhu, Professor of first division of Hepatobillary and Pancreatic Surgery of Second Affiliated Hospital, Kunming Medical University, 112 kunrui road, Kunming, Yunnan 650101, China, Tel: 008618487327303; E-mail: zhhong519@163.com

Received date: April 26, 2016; Accepted date: June 21, 2016; Published date: June 28, 2016

Copyright: (c) 2016 Asghar F, et al. This is an open-access article distributed under the terms of the Creative Commons Attribution License, which permits unrestricted use, distribution and reproduction in any medium, provided the original author and source are credited.

\begin{abstract}
One of the most common diseases that can affect human beings is Diabetes Mellitus. To that, Pancreas transplantation is the best known treatment so far but it also has some limitations. One of the most common reasons for failure is Thrombosis of pancreatic graft after transplantation. This review paper offers a brief history of transplantation and summary of those factors which can cause thrombosis of a pancreatic graft. There are two major groups for these factors; a) pre transplantation and b) post transplantation risk factors. The existing literature on thrombosis of pancreatic graft highlights those critical factors which could be one of the causes for thrombosis in a pancreatic graft. Pre transplantation risk factors include age of donor and recipient, gender of recipient, medical history of donor and recipient, ABO identity, duration of cold ischemia, administration of steroids and liquid of conservation. On the other hand, post-operative factors for thrombosis of pancreatic graft include venous anastomosis, microcirculation of graft, post-operative Von willebrand factor, post-operative hyperinsulinemia and type of pancreas transplantation. This review offers guidelines for pancreas transplantation in the light of these pre transplantation and post transplantation risk factors, so that surgeons can reduce the risk of thrombosis in a pancreatic graft.
\end{abstract}

Keywords: Transplantation; Thrombosis; Diabetes mellitus; Pancreas

\section{Introduction}

Diabetes Mellitus (DM) is the most common but critical disease which has affected the human beings significantly across the globe. The discovery of Insulin in 1922, medication used for the DM by two scientists, Banting and Best, has changed the prognosis of type-I disease from lethal to chronic. Though the exogenous administration of insulin does not allow perfect control of diabetes in long term, but with further research it is found that the degenerative complications induced by diabetes have a strong relationship with the quality of glycemic control [1]. Otherwise, diabetes can cause major macrovascular and micro-vascular complications. The best way to manage diabetes type-I is by pancreatic transplantation [2,3]. Kelly et al. [4] in December 1966, for the first time, performed pancreas transplantation with a renal graft to treat a type-I diabetes patient with uremia at the Hospital of the University of Minnesota, United States. Till 1980s, the pancreatic transplantation was being done just in a few centers of the United States and Europe. The introduction of the immunosuppressants tacrolimus and mycophenolate mofetil in 1994; the evolution of surgical techniques and the routine use of a preserving solution at the University of Wisconsin concluded with a significant improvement of the results and with the consequent increasing number of transplants performed in several countries [5].

The first pancreas transplantation in China was performed on 22 December 1982 at Tongji transplant Center, Wuhan [6]. One of the important outcomes of the pancreatic transplantations is to ensure the better quality of life in type-1 diabetes patients. In addition, the diabetes patients will get rid off from exogenous insulin and prevention of secondary complications of this type of diabetes such as retinopathy, neuropathy, nephropathy and vascular disease, besides protecting the transplanted kidney from developing diabetic nephropathy [7].

So far pancreatic transplantation is the best treatment for type 1 diabetes to establish a normoglycemia as effectively as a functional pancreas. But this treatment was limited by toxicity of immune suppressor treatment and surgical complications after transplantation. Half of the pancreatic graft fail due to technical failure in the first 6 months after transplantation [8,9]. Although improvement in pancreatic transplantation as treatment of type 1 diabetes came by the advancement in technology as in surgical technique, preservation of organs, and immunosuppression [10,11]. Thrombosis of pancreatic graft is still one of the most frequent surgical complications of the pancreatic graft and its pathogenesis is not still well understood $[12,13]$. Vascular thrombosis in responsible for the majority of these early graft losses with an estimate of 2:1 ratio between venous and arterial graft thrombosis [14].

The study presents that risk factors which cause thrombosis of pancreatic graft can be divided in two major groups. First, some complications which surgeon should enlist before the operation are listed in a major group as pre-transplant risk factor for venous thrombosis of the pancreatic graft second, those which are the causes of thrombosis after surgical process and we can enlist them as posttransplant risk factors.

\section{Pre Transplant Risk Factors}

The major pre-transplant risk factors we have deduced from the existing literature are:

Gender: Talking thrombosis it is noted that estrogen plays an important role in females but those who are below 50 years of age are less prone to have thrombosis and the same is reported in case of 
pancreatic graft transplantation. In most studies, venous thrombosis is more frequent in male patients as compare to their female counterparts. One of the critical complications is the narrowness of the male pelvis as compared to the female [15].

Age of donor and recipient: Many authors agree that the age plays an important role for the transplant survival both the age of donor and recipient the accepted higher limit is 45 years. Age more than this limit is not suitable for long term survival of a pancreatic graft $[16,17]$. The atherosclerosis is the phenomenon associated with age particularly involving the donor vessels used for arterial reconstruction of the pancreas graft [14]. On the other hand, it has been pointed out that the age of the receiver less than 45 years of age is associated with a satisfactory cardiovascular state has a major importance for the immediate success of the grafts and the long-term function of the pancreatic graft [18]. The Western literature identified that 45 years age is a set criteria for pancreas transplantation [19]. But other recent studies came with a different result and prove that patient with older age should be consider as potential candidates for allograft pancreas transplantation with good medical assessment [20,21]. 3 years survival rate in relationship to recipient and donor is represented as young-toyoung $>$ young-to-old $>$ old-to-young $>$ old-to-old [22].

Medical history of donor and recipient: Recent studies agree that medical history of donor and recipient plays a crucial role in thrombosis after transplantation. The donor with the history cerebrovascular can cause brain death, obesity, and presence of shock at the time of death has been cited as donor risk factors for subsequent pancreas graft thrombosis. Vascular disease in the recipient and certainly support graft thrombosis (thrombophilia), whether definitively diagnosed or based upon history alone, also increase risk in the recipient [14]. Diabetes itself is reported as a risk factor for thrombophilia and it is reported that $80 \%$ of patients with diabetes die from thrombotic complications. Diabetes is associated with abnormalities in nearly every component of the coagulation system which include platelets, vascular endothelium, coagulation factors, anticoagulants, and fibrinolysis [23].

Donors organ donated after cardiac death (DCD) and Organ donated after brain death (DBD) is a major debate between a lot of authors, mostly prefer is DBD, but it is said that DCD is showing the same results of graft survival and those donors should be consider to be safe for SPK to increase the donor pool meanwhile reducing waiting time for a patient but those cases which were failed thrombosis was found the major cause of graft failure in those patients was reported $12.8 \%$ for DCD Vs $6.1 \%$ in case of DBD [24]. For thrombosis point of view, DBD is considered to be safer as compared to DCD.

Obesity is a major phenomenon related with thrombosis for pancreatic graft in recipient, it is reported that in patients with BMI more than 24.9 chances of thrombosis are double then those with BMI less than 24.9 [25]. Cessation of smoking, prophylactic heparinization, monitoring of respiratory and cardiac status and prophylactic antibiotics are the recommendation to lower the surgrical risk in obese patients [26].

$\mathrm{ABO}$ identity: According to existing literature, it is seen that regarding $\mathrm{ABO}$ identity between receiver and donor is desirable fact [27]. Although transplantation has been reported in some nonidentical $\mathrm{ABO}$ donor and recipient successful to a certain period of time but the authors call it a coincidence and are unable to describe its role in venous thrombosis. ABO identical pair is preferred for transplantation of pancreas to avoid any thrombotic complication [17].
Duration of cold ischemia: The longest reported duration of cold ischemia is 34 hours with a successful pancreas transplant. Most researchers do not find any correlation for duration of cold ischemia and possible complications if duration is lower than 24 hours $[13,15]$. Some recent authors state that prolonged duration more than 12-24 hours can be a risk factor for thrombosis of pancreatic graft [28]. So, we conclude that surgeon should try to transplant the graft as early as possible within the time limit of 24 hours otherwise it is considered as a risk factor for thrombosis of the pancreatic graft.

Administration of steroids: It is recommended to administer the high amounts of steroids, to prevent the edema of the gland which appears during perfusion with the cooling liquid and during mobilization of the internal organs [15]. By reducing edema of gland we can reduce the risk of thrombosis.

Liquid of conservation: The liquid of conservation the solution of VIASPAN $^{\circledR}$, (University of Wisconsin organ preservation solution), unanimously considered as the best, as it makes possible to preserve pancreas for 30 hours [29] but some other studies suggest the same efficacy for pancreas transplantation with histidine-tryptophanketoglutarate (HTK) [30].

Post transplantation risk factor: The study in hand enlists some major risk factors that should or can be managed after the transplantation is done. By keeping these factors in attention and addressing them in a proper way can reduce the risk of thrombosis in a pancreatic graft.

Venous anastomosis: Venous anastomosis is a key factor for thrombosis. There are two different processes recommended for venous anastomosis as purpose to decrease the risk of venous thrombosis. Some authors suggest a venous anastomosis between a short portal segment and an iliac vein well mobilized, after the ligature of the hypogastric branches. By this, portal angioplasty [31] can be avoided. Mostly preferred way is a long portal segment (possibly extended in ex vivo), anastomosed with an external or primitive iliac vein without excessive mobilization and section of the hypogastric branches [32].

Microcirculation: Pancreas has a reduced circulatory flow as compare to other solid organs like liver and kidney that is 1.3 percent of the cardiac total cardiac flow. This ratio is not changed in the graft, regardless of the technique is used. The changes of microcirculation in grafted pancreas play an important role in the occurrence of venous thrombosis and are represented by the following sequence: reperfusion - cellular death - edema - increase in local resistance to blood flow [12]. This local resistance can lead to the thrombosis in a pancreatic graft. So regarding the surgical approach in the case of venous thrombosis of the pancreatic graft, the majority of teams prefer explanation to reperfusion $[12,33,34]$. Thrombosis may also be partial or complete in regard to the extent of involvement of the pancreas [35]. Partial occlusive thrombosis, which is probably underreported, occurs more frequently than complete thrombosis and pancreas graft survival is much more likely [36]. If the partial thrombosis is early diagnosed it can only be treated with Aspirin and reperfusion can be reduced to anticoagulant medication for 3 months in total venous thrombosis $[36,37]$. Thrombectomy associated with heparin followed by an oral anticoagulation is mentioned as another effective treatment for reperfusion [38]. Hypotension of pancreatic graft is a cause for thrombosis if pancreatic graft is well perfused incidence of thrombosis can me addresses properly [39]. 
Post-operative Von willebrand factor: Von willebrand factor is associated with thrombosis so it should monitored carefully after the surgery as it is reported to be high in the patients found with venous thrombosis of pancreatic graft [40].

Post-operative hyperinsulinemia: In all studies, the occurrence of venous thrombosis is fast, most frequently between 12 hours and 5 days. Hyperinsulinemia settles soon after declamping of graft. Insulin favors platelet aggregation and induces a state of hypercoagulability which might be a factor towards thrombosis [41].

\section{Different types of pancreas transplant}

Registered data suggest that simultaneous pancreas and kidney (SPK) transplant recipients have less pancreas graft thrombosis compared to pancreas after kidney (PAK) or pancreas transplant alone (PTA) recipients [42]. Best results are said when pancreas transplantation is done simultaneously with kidney the anticoagulant effects of uremia and lower risk for acute rejection associated can be a reason for lower risk for vascular thrombosis.

Anticoagulation therapy: Anti-coagulation therapy plays a key role in reducing the incidence of thrombosis [42,43]. Low-molecularweight heparin LMWH and unfractionated heparin UFH were on trial for DVT $[44,45]$. Experimental study reveals that once daily fixed dose of LMWH is effective to prevent pancreatic graft thrombosis [46]. LMWH like bemiparin suggested treatment for DVT, diabetic complications like ulcer on lower extremity and other surgical thrombotic complications [47].

\section{Conclusion}

The major problem which can occur after transplantation is the Thrombosis of pancreas. To address the issue, this study extends guidelines helping surgeons to minimize the chances of thrombosis. The existing literature on medical history suggests that age of donor and recipient should be less than 45 years of age, apart from the duration of cold ischemia and use of proper solution of conservation. The study further suggests that Post-operative von willebrand factor and hyper insulinemia should be well controlled. SPKT show best result rather than PAK and PTA.

\section{References}

1. Sutherland DE, Gores PF, Farney AC, Wahoff DC, Matas AJ, et al. (1993) Evolution of kidney, pancreas, and islet transplantation for patients with diabetes at the University of Minnesota. Am J Surg 166: 456-491.

2. Sutherland DE, Gruessner RW, Dunn DL, Matas AJ, Humar A, et al. (2001) Lessons learned from more than 1,000 pancreas transplants at a single institution. Ann Surg 233: 463-501.

3. Mittal S, Gough SC (2014) Pancreas transplantation: a treatment option for people with diabetes. Diabet Med 31: 512-521.

4. Kelly WD, Lillehei RC, Merkel FK, Idezuki Y, Goetz FC, et al. (1967) Allotransplantation of the pancreas and duodenum along with the kidney in diabetic nephropathy. Surgery 61: 827-837.

5. Gruessner AC, Sutherland DE (2005) Pancreas transplant outcomes for United States (US) and non- US cases as reported to the United Network for Organ Sharing (UNOS) and the International Pancreas Transplant Registry (IPTR) as of June 2004. Clin Transplant 19: 433-455.

6. Chen S, Xia SS, Tang JZ, Qin XF (1986) Segmental pancreas allograft: a report of one case surviving more than one year with functioning graft. J Tongji Med Univ 6: 151-155.

7. Mauer M, Fioretto P (2013) Pancreas transplantation and reversal of diabetic nephropathy lesions. Med Clin North Am 97: 109-114.
8. Humar A, Ramcharan T, Kandaswamy R, Gruessner RW, Gruessner AC, et al. (2004) Technical failures after pancreas transplants: why grafts fail and the risk factors--a multivariate analysis. Transplantation 78: 1188-1192.

9. Troppmann C (2010) Complications after pancreas transplantation. Curr Opin Organ Transplant 15: 112-118.

10. Kandaswamy R, Stock PG, Skeans MA, Gustafson SK, Sleeman EF, et al. (2013) OPTN/SRTR 2011 Annual Data Report: pancreas. Am J Transplant 13 Suppl 1: 47-72.

11. McLaren AJ, Friend PJ (2003) Trends in organ preservation. Transpl Int 16: 701-708.

12. Douzdjian V, Abecassis MM, Cooper JL, Smith JL, Corry RJ, et al. (1993) Incidence, management and significance of surgical complications after pancreatic transplantation. Surg Gynecol Obstet 177: 451-456.

13. Sollinger HW (1994) Current status of simultaneous pancreas-kidney transplantation. Transplant Proc 26: 375-378.

14. Farney AC, Rogers J, Stratta RJ (2012) Pancreas graft thrombosis: causes, prevention, diagnosis, and intervention. Curr Opin Organ Transplant 17: 87-92.

15. Grewal HP, Garland L, Novak K, Gaber L, Tolley EA, et al. (1993) Risk factors for postimplantation pancreatitis and pancreatic thrombosis in pancreas transplant recipients. Transplantation 56: 609-612.

16. Gruessner RW, Troppmann C, Barrou B, Dunn DL, Moudry-Munns KC, et al. (1994) Assessment of donor and recipient risk factors on pancreas transplant outcome. Transplant Proc 26: 437-438.

17. Ionescu C, Wolf P, Ellero B, Mihaescu G (2007) The venous thrombosis of the pancreatic graft. J Gastrointestin Liver Dis 16: 287-292.

18. Tesi RJ, Elkhammas EA, Henry ML, Davies EA, Ferguson RM, et al. (1994) Pattern of graft loss after combined kidney-pancreas transplant. Transplant Proc 26: 425-426.

19. European Best Practice Guidelines (2000) "Evaluation, selection and preparation of the potential transplant recipient. Nephrology Dialysis Transplantation 15: 3 .

20. Afaneh C, Rich BS, Aull MJ, Hartono C, Leeser DB, et al. (2011) Pancreas transplantation: does age increase morbidity? J Transplant 2011: 596801.

21. Schenker P, Vonend O, Krüger B, Klein T, Michalski S, et al. (2011) Longterm results of pancreas transplantation in patients older than 50 years. Transpl Int 24: 136-142.

22. Kayler LK, Wen X, Zachariah M, Casey M, Schold J, et al. (2013) Outcomes and survival analysis of old-to-old simultaneous pancreas and kidney transplantation. Transpl Int 26: 963-972.

23. Carr ME (2001) Diabetes mellitus: a hypercoagulable state. J Diabetes Complications 15: 44-54

24. Salvalaggio PR, Davies DB, Fernandez LA, Kaufman DB (2006) Outcomes of pancreas transplantation in the United States using cardiacdeath donors. Am J Transplant 6: 1059-1065.

25. Sampaio MS, Reddy PN, Kuo HT, Poommipanit N, Cho YW, et al. (2010) Obesity was associated with inferior outcomes in simultaneous pancreas kidney transplant. Transplantation 89: 1117-1125.

26. Pasulka PS, Bistrian BR, Benotti PN, Blackburn GL (1986) The risks of surgery in obese patients. Ann Intern Med 104: 540-546.

27. Mouquet C, Babinet J, Barrou B, Benalia H, Bitker MO, et al. (1994) Hemolysis after whole pancreas transplantation. Transplant Proc 26: 430-431.

28. Douzdjian V, Abecassis MM, Cooper JL, Argibay PF, Smith JL, et al. (1993) Pancreas transplant salvage after acute venous thrombosis. Transplantation 56: 222-223.

29. Belzer FO, Ploeg RJ, Knechtle SJ, D'Alessandro AM, Pirsch JD, et al. (1994) Clinical pancreas preservation and transplantation. Transplant Proc 26: 550-551.

30. Fridell JA, Agarwal A, Milgrom ML, Goggins WC, Murdock P, et al. (2004). Comparison of histidine-tryptophan-ketoglutarate solution and university of wisconsin solution for organ preservation in clinical pancreas transplantation. Transplantation: 27: 1304-1306. 
31. Sollinger HW, Geffner SR (1994) Pancreas transplantation. Surg Clin North Am 74: 1183-1195.

32. Hopt UT, Büsing M, Schareck W, Pfeffer F, Blumenstock I, et al. (1993) Prevention of early postoperative graft thrombosis in pancreatic transplantation. Transplant Proc 25: 2607-2608.

33. Douzdjian V, Abecassis MM, Cooper JL, Argibay PF, Smith JL, et al. (1993) Pancreas transplant salvage after acute venous thrombosis. Transplantation 56: 222-223.

34. Troppmann C, Dunn DL, Najarian JS, Sutherland DE, Gruessner AC, et al. (1994) Operative reintervention following early complications after pancreas transplantation. Transplant Proc 26: 454.

35. Fisher RA, Munda R, Madden R (1993) Pancreas transplant functional salvage after segmental vascular thrombosis. Transplant Proc 25: 2138-2140.

36. Ciancio G, Cespedes M, Olson L, Miller J, Burke GW, et al. (2000) Partial venous thrombosis of the pancreatic allografts after simultaneous pancreas-kidney transplantation. Clin Transplant 14: 464-471.

37. Delis S, Dervenis C, Bramis J, Burke GW, Miller J, et al. (2004) Vascular complications of pancreas transplantation. Pancreas 28: 413-420.

38. Ciancio G, Julian JF, Fernandez L, Miller J, Burke GW, et al. (2000) Successful surgical salvage of pancreas allografts after complete venous thrombosis. Transplantation 70: 126-131.

39. Ramessur Chandran S, Kanellis J, Polkinghorne KR, Saunder AC, Mulley WR, et al. (2013) Early pancreas allograft thrombosis. Clin Transplant 27: 410-416.

40. Kessler L, Wiesel ML, Boudjema K, Lutun E, Moulin B, et al. (1998) Possible involvement of Von Willebrand factor in pancreatic graft thrombosis after kidney-pancreas transplantation: a retrospective study. Clin Transplant 12: 35-42.

41. Kessler L, Boudjema K, Wolf P, Reville P, Pinget M, et al. (1996) [Benefits and limitations of pancreas transplantation in insulin-dependent diabetics: a study apropos of 26 patients]. Rev Med Interne 17: 117-124.

42. Fertmann JM, Wimmer CD, Arbogast HP, Illner WD, Tarabichi A, et al. (2006) Single-shot antithrombin in human pancreas-kidney transplantation: reduction of reperfusion pancreatitis and prevention of graft thrombosis. Transpl Int 19: 458-465.

43. Nader A, Büsing M, Blumenstock I, Heimburger N, Jochum M, et al. (1993) Coagulation disorders after reperfusion of pancreatic allografts. Transplant Proc 25: 1174-1175.

44. Gould MK, Dembitzer AD, Doyle RL, Hastie TJ, Garber AM, et al. (1999) Low-molecular-weight heparins compared with unfractionated heparin for treatment of acute deep venous thrombosis. A meta-analysis of randomized, controlled trials. Ann Intern Med 130: 800-809.

45. Levine M, Gent M, Hirsh J, Leclerc J, Anderson D, et al. (1996) A comparison of low-molecular-weight heparin administered primarily at home with unfractionated heparin administered in the hospital for proximal deep-vein thrombosis. N Engl J Med 334: 677-681.

46. Schenker P, Vonend O, Ertas N, Wunsch A, Schaeffer M, et al. (2009) Incidence of pancreas graft thrombosis using low-molecular-weight heparin. Clin Transplant 23: 407-414.

47. Ciccone MM, Cortese F, Corbo F, Corrales NE, Al-Momen AK, et al. (2014) Bemiparin, an effective and safe low molecular weight heparin: a review. Vascul Pharmacol 62: 32-37. 